\title{
EED \\ Knowledge Transfer and Technology Diffusion
}

EDITED BY

PAUL L. ROBERTSON

AND

DAVID JACOBSON

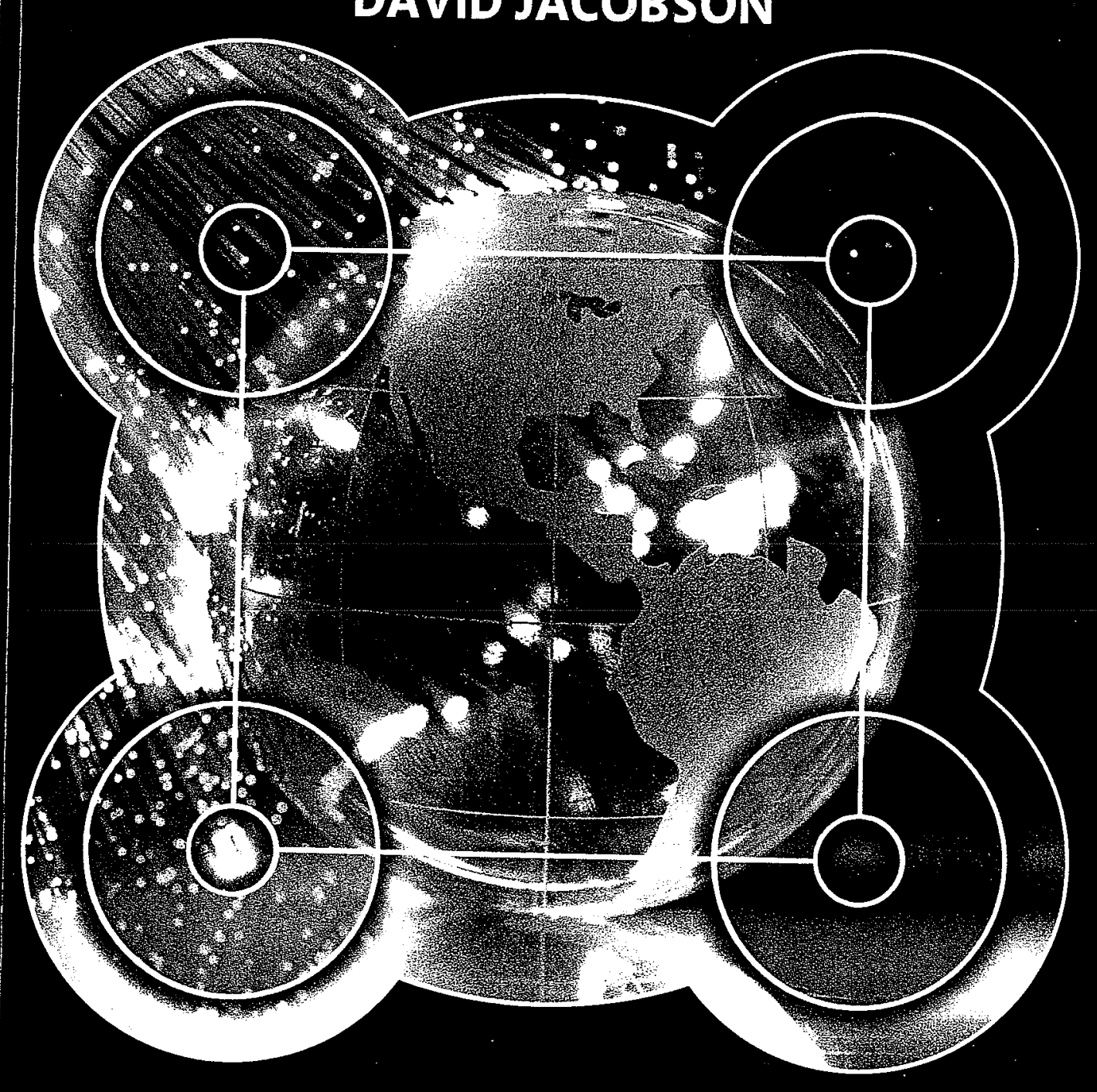




\section{Knowledge Transfer and Technology Diffusion}

This important book is about the origins and diffusion of innovation, in theory and in practice. The practice draws on a variety of industries, from electronics to eyewear, from furniture to mechatronics, in a range of economies including Europe, the USA, and China.

The eminent contributors investigate. how the latest technologies diffuse through the economy, helping to reinvigorate seemingly old and stagnant industries in the process. Examples drawn from Asia and Europe show how countries like China and India are increasingly able to catch up with, or even surpass, industrialized nations in Europe and North America, in some cases by becoming technological pioneers. The book also examines the effects of new information and communications technologies on regional economies, especially in Western Europe. The themes and findings are summarized and evaluated in an extensive introductory chapter.

Scholars of innovation from a variety of disciplines, including management, economics, and human resources will find this study insightful. Postgraduate students in industrial studies, industrial dynamics, and industrial development, including both advanced and industrializing countries, will also find much of interest to them in this timely book.

Paul L. Robertson is at the University of Tasmania, Australia and David Jacobson is Professor of Economics at Dublin City University, Ireland.

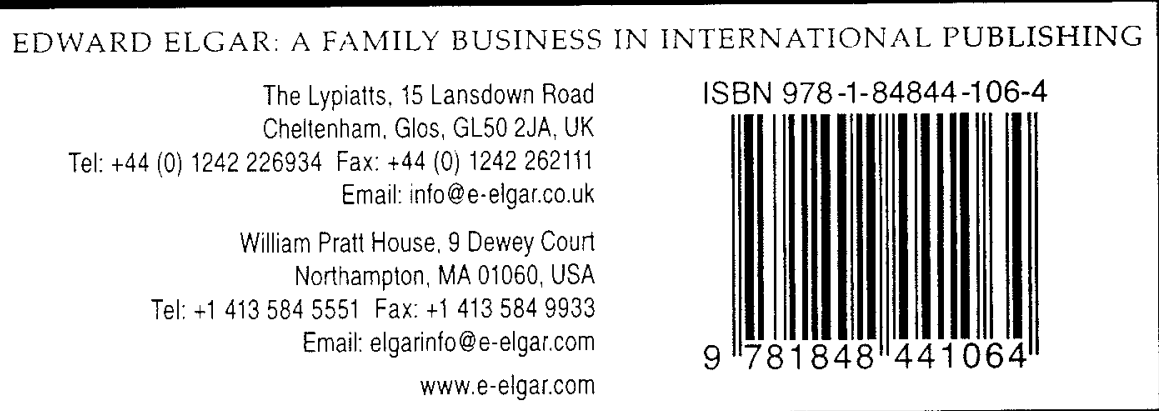




\section{Knowledge Transfer and Technology Diffusion}

Edited by

Paul L. Robertson

University of Tasmania, Australia

David Jacobson

Dublin City University, Ireland

\section{Edward Elgar}

Cheltenham, UK • Northampton, MA, USA 

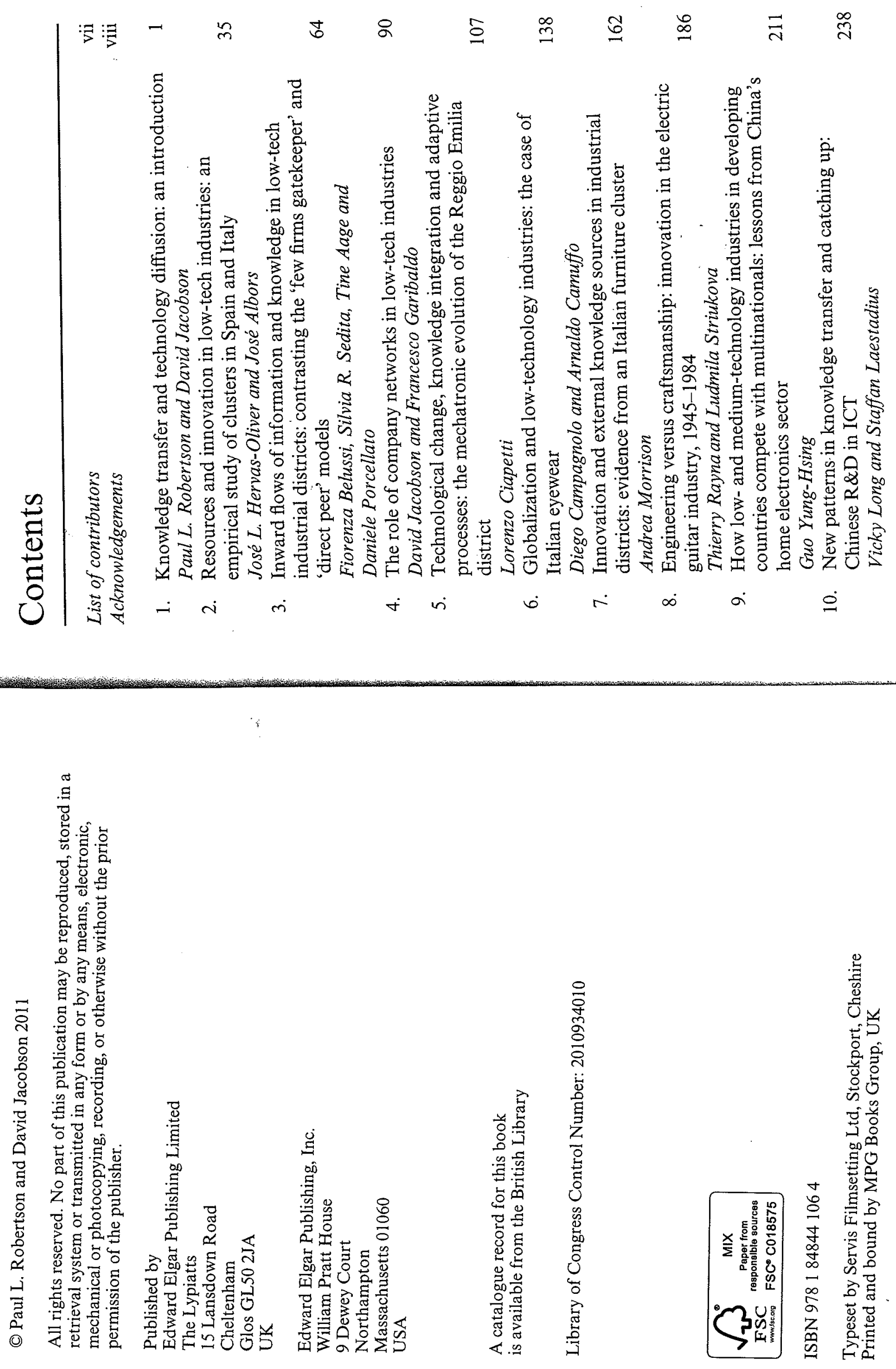


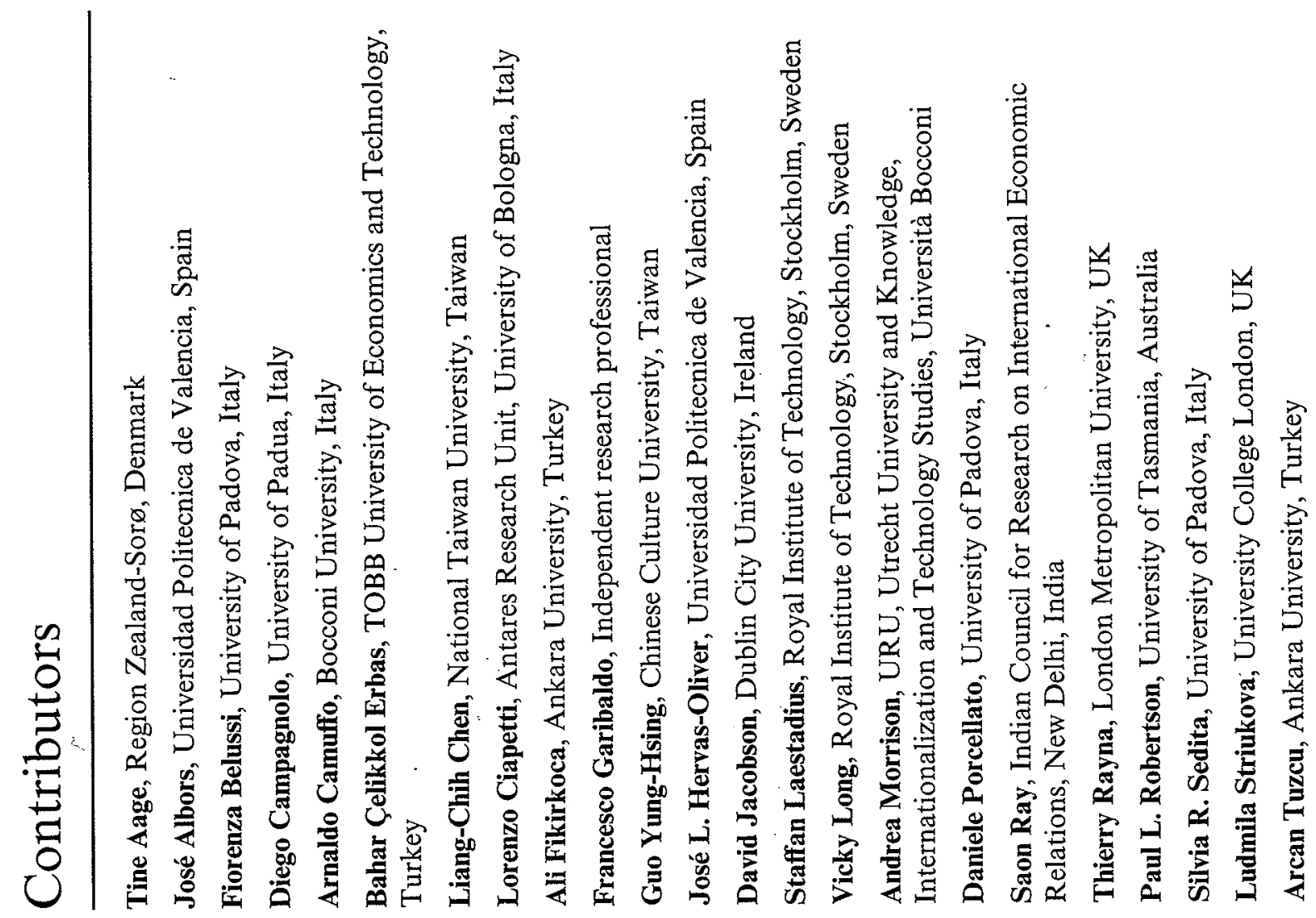

$\stackrel{i}{\sim} \stackrel{m}{m}$

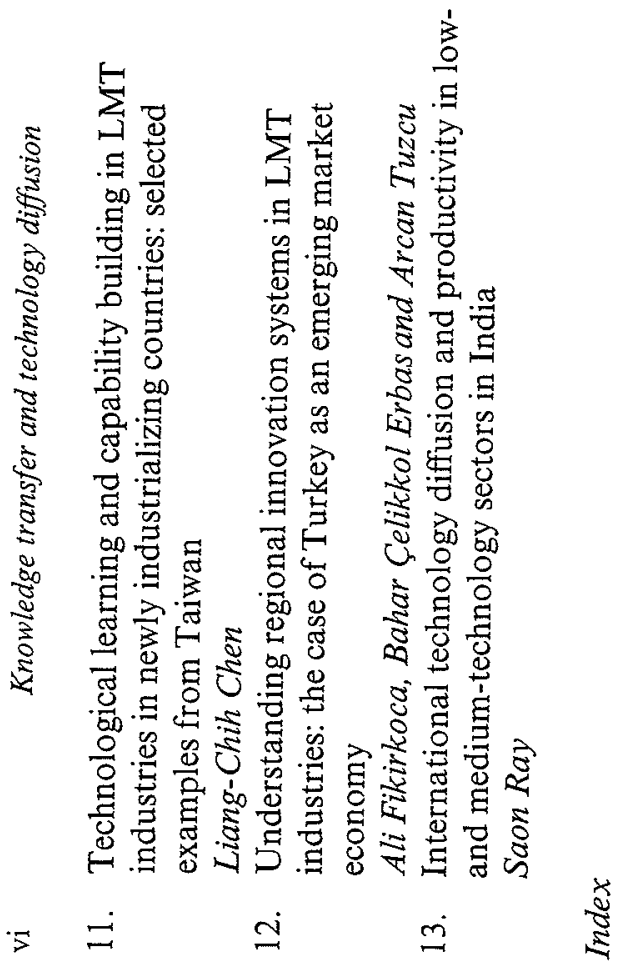

